\title{
Alcance y derrotabilidad de las reglas jurídicas*
}

\section{Scope and Defeasibility of Legal Rules}

Fabio Enrique Pulido ORTIZ**

\section{Resumen:}

En este artículo se analiza el alcance práctico de las reglas (AP) y su relación con las reglas de derrotabilidad (RD). Primero, se afirma que determinar el AP depende tanto de las reglas secundarias del sistema jurídico como del dominio limitado de las autoridades. Segundo, se muestra que las reglas secundarias pueden incluir o excluir las razones justificatorias de las reglas y, en esos contextos en donde esas razones no son excluidas, es posible que ellas generen excepciones implícitas, las cuales no pueden ser identificadas de manera anticipada. Tercero, se concluye que la derrotabilidad de la reglas es una propiedad contingente que depende de dos elementos: $a$ ) la presencia de razones justificatorias que no son excluidas de acuerdo con las reglas secundarias y el límite de dominio de las autoridades, y $b$ ) que las consecuencias normativas de esas razones no puedan ser identificadas ex-ante.

\section{Palabras clave:}

Normatividad del derecho, reglas jurídicas, derrotabilidad, razón práctica, razones para la acción.

* Artículo recibido el 20 de abril de 2017 y aprobado para su publicación el 13 de octubre de 2017.

** Abogado. Magister en derecho. Doctor en derecho (área: filosofía del derecho). Director del Departamento de Teoría Jurídica y de la Maestría en Derecho Constitucional de la Facultad de Derecho y Ciencias Políticas de la Universidad de La Sabana. 
Esta revista forma parte del acervo de la Biblioteca Jurídica Virtual del Instituto de Investigaciones Jurídicas de la UNAM

FABIO ENRIQUE PULIDO ORTIZ

\section{Abstract:}

The article analyses the practical scope (PS) of legal rules and its relation with the defeasibility of the rules (DR). First, I argue that to determine the PS depends on three factors: a) the content of secondary rules, b) the legal systems and, c) establishing the specific and legitimate jurisdiction of the authorities. Second, I suggest that the PS can include or exclude the justificatory reasons of rules and, in those contexts where such reasons are not excluded, it is possible that they generate implicit exceptions that cannot be identified in advance. Third, the author concludes that DR is a contingent property that depends on two elements: a) the presence of justificatory reasons - that are not excluded according to secondary rules and the limited domain of authorities - and, b) that the normative consequences of such reasons cannot be identified ex-ante.

\section{Keywords:}

Normativity of law, legal rules, defeseability, practical reason, reasons for action. 
ALCANCE Y DERROTABILIDAD DE LAS REGLAS JURÍDICAS

SUMARIO: I. Introducción. II. El alcance práctico de las reglas. III. Relaciones con las razones no excluidas: antinomias y excepciones. IV. La derrotabilidad de las reglas. V. Conclusiones. VI. Bibliografía.

\section{INTRODUCCIÓN}

La teoría jurídica contemporánea sostiene que en la explicación de la normatividad del derecho se debe dar cuenta de la forma en que las reglas jurídicas son razones para la acción. Según Joseph Raz, esas reglas constituyen un tipo especial de razones para la acción: razones protegidas; a saber: razones que, además de definir cómo se debe actuar, excluyen determinado conjunto de razones relevantes. ${ }^{1}$ Sin embargo, los críticos afirman que la tesis de las razones protegidas no logra dar cuenta del hecho de que las normas jurídicas pueden ser superadas o derrotadas por otros tipos de razones ( $v . g r$., razones morales). ${ }^{2} \mathrm{Al}$ observarse que las normas jurídicas pueden ser derrotadas por una razón (o conjunto de razones) implica - según los críticos- que las reglas jurídicas no cumplen una función excluyente en el razonamiento práctico. ${ }^{3}$

El problema, en otras palabras, consiste en definir si es posible afirmar que las reglas jurídicas tienen una función excluyente en el razonamiento práctico y reconocer, al mismo tiempo, la existencia de razones capaces de superarlas. Ahora bien, una respuesta satisfactoria a este problema debe partir de una adecuada caracterización de la relación de las reglas con aquellas razones que son capa-

1 Raz, Joseph, The Authority of Law. Essays on Law and Morality, Oxford, Clarendon Press, 1979, p. 18; Raz, Joseph, Practical Reason and Norms, 2a. ed., Oxford, Oxford University Press, 1990, p. 191.

2 Perry, Stephen R., "Judicial Obligation, Precedent and the Common Law", $O x$ ford Journal of Legal Studies, núm. 2, 1987, pp. 215-257; Postema, Gerald, "Law's Autonomy and Public Practical Reason", en George, Robert P., The Autonomy of law. Essays on legal positivism, Oxford, Oxford University Press, 1996, pp. 57-78; y Martin, Margaret, Judging positivism, Oxford, Hart Publishing, 2014, pp. 25, 26, 36-40.

3 Moore, Michael, “Authority, Law and Razian Reasons", S. Cal. Law. Rev, núm. 3, 1989, pp. 827-896, y Bayón, Juan C., La normatividad del derecho: deber jurídico y razones para la acción, Madrid, Centro de Estudios Constitucionales, 1991. 
ces de superarlas. Con este problema en mente, el presente trabajo se propone analizar el alcance práctico de las reglas (AP) y su relación con la derrotabilidad de las reglas (DR). Se argumentará a favor de las siguientes tesis: en primer lugar, se mostrará que la respuesta a la cuestión acerca de AP (i. e. la definición del conjunto de razones excluidas por las reglas) depende del contenido de las reglas secundarias de los ordenamientos jurídicos y de la definición del dominio limitado de la jurisdicción legítima de las autoridades jurídicas. En segundo lugar, se señalará que el AP de las reglas puede incluir o excluir - como consideraciones relevantes al momento de definir lo que exigen las reglas - a las razones subyacentes o justificatorias. En aquellos contextos en los que las razones subyacentes no son excluidas, es posible que esas razones generen excepciones implícitas no identificables de antemano. En tercer lugar, se sostendrá que la DR (i. e. la posibilidad de que las razones subyacentes superen a las reglas) es una propiedad contingente de las reglas jurídicas que depende de dos factores: $a$ ) que de acuerdo con las reglas secundarias del sistema jurídico respectivo y de la tesis del dominio limitado de la autoridad, las razones subyacentes no sean excluidas, y $b$ ) que las consecuencias normativas de esas razones no puedan ser identificadas y reconstruidas de antemano.

El artículo se desarrollará de la siguiente manera: en la primera parte, y a partir de un análisis crítico de las ideas de Joseph Raz, se explica el AP. Luego se señala que en la explicación de las relaciones entre las reglas y las razones no excluidas son adecuadas las nociones de antinomia y excepción. En tercer lugar, y a través del estudio de los trabajos de Juan C. Bayón, Jorge L. Rodríguez y Frederick Schauer, se explica el concepto de derrotabilidad de las reglas (DR) y se plantean las conclusiones.

\section{EL ALCANCE PRÁCTICO DE LAS REGLAS}

El razonamiento práctico es la capacidad humana de definir las razones que justifican determinadas acciones o decisiones. ${ }^{4}$ Joseph

4 Los filósofos suelen distinguir entre razonamiento práctico y teórico. Las concepciones contemporáneas entienden que la diferencia entre lo práctico y lo teórico 
Raz plantea que existen dos modelos generales de razonamiento práctico. En el primer modelo, la justificación de la acción del individuo depende de su balance de razones de primer orden. Según este modelo, los agentes deben actuar de acuerdo con el principio de razón práctica, según el cual se deben considerar todas las razones relevantes, de manera tal que los conflictos entre razones (de primer orden) se resuelvan por el peso relativo de éstas. ${ }^{5}$

No obstante, para Raz, el primer modelo no es suficiente para explicar las diversas y habituales situaciones prácticas de conflictos entre razones. ${ }^{6}$ Para dar cuenta de la complejidad del razonamiento práctico, Raz considera necesario distinguir entre razones de primer orden y de segundo orden. Las de primer orden son razones para actuar o no actuar de determinada manera, y las de segundo orden son razones para actuar o no actuar según otras razones. De este modo, las razones de segundo orden se diferencian de las de primer orden por su rol normativo, positivo o negativo. La función o el carácter normativo negativo de las razones está presente en la idea de las razones excluyentes. ${ }^{7}$ Estas razones excluyentes, por tanto, son razones de segundo orden negativas, es decir, que cumplen la función normativa de excluir una razón o un conjunto de razones que de otra manera serían relevantes en el balance general de razones.

Por lo anterior, mientras que los conflictos entre razones de primer orden se resuelven por el peso relativo de las razones en competencia, los conflictos entre razones de primer orden y razones excluyentes se resuelven a favor de estas últimas, por la función que

radica en dos asuntos: las consecuencias de uno y otro, y el contraste respectivo entre dos referentes normativos. Sobre lo primero, la consecuencia del razonamiento teórico es la formación y modificación de las creencias de los individuos, y la del práctico, la formación y modificación de razones para actuar. Sobre lo segundo, la diferencia entre lo teórico y lo práctico implica, por un lado, la regulación de las creencias, y, por otro, la regulación de la acción intencional (Wallace, R. Jay, "Practical Reason", en E. Zalta (ed.), The Stanford Encyclopedia of Philosophy, consultado el 16 de marzo de 2016, en: https://plato.stanford.edu/archives/sum2014/entries/ practical-reason/.

5 Raz, Joseph, Practical Reason and Norms, cit., pp. 36 y 37.

6 Ibidem, pp. 37-39.

7 Ibidem, pp. 39 y 40. 
tienen en el razonamiento práctico, y no por su peso relativo. De conformidad con el segundo modelo, los individuos no deben actuar de acuerdo con un balance general de razones, si las razones determinantes para el balance son excluidas por una razón excluyente. ${ }^{8}$

En resumen, las razones de primer orden son consideraciones a favor o en contra de una acción determinada. Las razones de segundo orden son razones sobre razones, y en particular razones acerca de cómo tratar a las razones de primer orden. ${ }^{9}$ Las razones de segundo orden pueden, a su vez, ser incluyentes o excluyentes. Las razones de segundo orden incluyentes definen bajo qué razón o conjunto de razones se debe actuar. Las razones de segundo orden excluyentes definen que no se debe actuar con base en una razón o un conjunto de razones. Sobre la base de este planteamiento, Raz formula que la combinación de una razón de primer orden con una razón de segundo orden excluyente configura una razón protegida. Así, las reglas jurídicas (i. e. las reglas proferidas por las autoridades jurídicas) son, según Raz, razones protegidas: razones que además de indicar cómo se debe actuar, excluyen a un conjunto de razones. ${ }^{10}$

Según la explicación del razonamiento práctico formulada por Raz, existen tres clases de conflictos entre razones: (1) conflictos entre razones de primer orden; (2) conflictos entre razones de segundo orden, y (3) conflictos entre razones de primer orden y de segundo orden excluyentes. Los conflictos de los tipos (1) y (2), según el autor, se resuelven de acuerdo con el peso que resulte del balance de las razones en juego. Por el contrario, los conflictos del tipo (3) se resuelven, por definición, a favor de las razones excluyentes. Sin embargo, la tesis de las razones protegidas no significa que prevalezcan sobre todas las razones de primer orden, sino sólo sobre aquellas que, en efecto, son excluidas. Esto quiere decir que las razones protegidas, en tanto razones de segundo orden, tienen un AP referido a la definición del conjunto de razones que son excluidas. Así las cosas, en las siguientes líneas se precisarán algunas cuestio-

8 Ibidem, p. 40.

9 Ibidem, pp. 39-48.

10 Ibidem, p. 191. 
nes que resultan fundamentales para comprender el AP de las reglas jurídicas. ${ }^{11}$

En primer lugar, se debe tener en cuenta que la función excluyente de las razones protegidas (y dentro de ellas las reglas jurídicas) se refiere a aquellas razones que harían diferencia práctica respecto de lo que debe ser hecho. Por lo tanto, sólo tiene sentido la noción de exclusión cuando se habla de razones relevantes. En efecto, sólo en situaciones en que las razones excluidas son relevantes para definir cómo se debe actuar, es posible hablar, en estricto sentido, de relevancia o diferencia práctica de las razones excluyentes. En otras palabras, la exclusión se puede referir a: (1) una razón - o conjunto de razones- que en todo caso habría sido derrotada en un balance general de razones, o (2) una razón - o conjunto de razones - que habría inclinado el balance general de razones, es decir, que sería relevante al momento de determinar cómo actuar. ${ }^{12}$ Sólo en el caso (2) se puede hablar, en rigor, de exclusión, o más precisamente, de relevancia normativa de la exclusión.

Ahora bien, la definición del conjunto de razones excluidas depende de una cuestión más compleja: ¿pueden las razones protegidas (y, en este sentido, las reglas jurídicas) excluir todas las razones objetivamente relevantes respecto de la acción exigida? Es posible ofrecer dos soluciones que, sin matices adicionales, resultan contradictorias.

De acuerdo con la primera solución, el derecho se caracteriza por ser "comprehensivo" (comprehensive), es decir, que pretende autoridad para regular cualquier tipo de comportamiento. ${ }^{13}$ Esto no significa que los ordenamientos jurídicos, en efecto, regulen todos los comportamientos, ni que tengan autoridad legítima para hacerlo. Significa, simplemente, que es posible que el derecho pretenda regular todo tipo de comportamiento. ${ }^{14}$ Según esto, el AP depende de

11 Antes de continuar, no sobra advertir una limitación metodológica: la explicación que se ofrece en este trabajo se limita a las reglas proferidas por las autoridades jurídicas.

12 Ibidem, pp. 40-45.

13 Ibidem, pp. 150 y 151.

14 Ibidem, p. 151. 
las decisiones de las autoridades jurídicas. Si el ordenamiento jurídico es comprehensivo, esto significa que las autoridades pueden pretender excluir todas las razones objetivamente relevantes, o limitar el alcance de la exclusión a un conjunto determinado de éstas.

De acuerdo con la segunda solución, si el alcance de la exclusión de una norma jurídica fuese respecto de todas las razones objetivamente relevantes para una acción determinada, se caería en el absurdo de que toda acción sería jurídica (o antijurídica), o de que siempre habría una razón jurídica para actuar o no actuar. Si las normas jurídicas excluyen a todas las razones relevantes para actuar, sería preciso afirmar que, por ejemplo, cuando un jugador de ajedrez decide cómo mover una ficha, estaría actuando y razonando jurídicamente, por cuanto ello sería una regla jurídica o haría parte de las razones excluidas. ${ }^{15}$

Entonces, ¿es posible que el derecho pretenda una exclusión de todas las razones relevantes y que, al mismo tiempo, no caiga en el absurdo de asumir que todo comportamiento es, de una u otra manera, jurídico? Para conciliar estas dos ideas se ha recurrido a la tesis del dominio limitado (limited domain thesis). ${ }^{16}$ Según esta tesis, la autoridad tiene la facultad de emitir directivas dentro de la esfera de su jurisdicción, es decir, dentro del rango de acciones sobre las cuales tiene derecho a gobernar. ${ }^{17}$ La jurisdicción de una autoridad determina tanto las acciones y personas que puede dirigir, como las consideraciones que es capaz de excluir. Por cuanto la autoridad legítima tiene una jurisdicción limitada, el alcance práctico de las reglas emitidas por ella es limitado, al menos respecto del rango de consideraciones, acciones y personas sobre las que la autoridad tiene la capacidad (moral) de gobernar. ${ }^{18}$

15 Raz, Joseph, Between Authority and Interpretation: on the Theory of Law and Practical Reason, Oxford, Oxford University Press, 2009, p. 380.

16 Ibidem, pp. 380-382, y Schauer, Frederick, "The limited domain of the law", Virginia Law Review, núm. 7, 2004, pp. 1909-1956.

17 Raz, Between Authority and Interpretation..., cit., pp. 380-382.

18 Endicott, Timothy, "Interpretation, jurisdiction, and the authority of law", American Philosophical Association Newsletter on Law and Philosophy, núm. 2, 2007, pp. 14-19. 
Para comprender la tesis del dominio limitado deben articularse dos ideas. Por una parte, que la jurisdicción de las autoridades jurídicas depende de las reglas secundarias del sistema, ${ }^{19} \mathrm{y}$, por otra, que la jurisdicción de las autoridades jurídicas depende de que, en efecto, se den los presupuestos de la autoridad legítima. ${ }^{20}$ Las reglas primarias definen cómo los individuos deben actuar o decidir, es decir, son razones de primer orden para hacer aquello que las reglas exigen, y las secundarias, por su parte, definen cómo las reglas primarias deben identificarse, modificarse o aplicarse. De acuerdo con esto, las reglas secundarias determinan la competencia de las autoridades para dictar reglas, y en esa misma línea, de ser fuente de razones de primer orden. Las reglas secundarias de competencia tienen, como resulta evidente, un contenido contingente, y así, pueden ampliar o reducir el AP de las reglas emitidas por autoridades reconocidas. $^{21}$

Por otra parte, Raz recurre a la concepción de la autoridad como servicio (service conception) para explicar la legitimidad de la autoridad. De acuerdo con esta concepción, seguir las reglas emitidas por una autoridad está justificado, siempre que se acredite que es más probable que los individuos que las siguen se conforman mejor con las razones que, en todo caso, justifican la acción, que cuando esos individuos deciden por ellos mismos (es decir, en ausencia de las directivas de la autoridad..$^{22}$ La concepción de la autoridad como servicio pretende captar lo que, según Raz, es fundamental en las autoridades prácticas: el desplazamiento racional de la toma de decisiones de una persona a otra. Para que este desplazamiento sea racional, los individuos deben carecer del mismo acierto (en comparación con la autoridad) para determinar, por sí mismos, lo que

19 Hart, H. L. A., The concept of law, 2a. ed., P. Bulloch y J. Raz (eds.), Oxford, Clarendon Press, 1994, pp. 81-91; Caracciolo, Ricardo, "El concepto de autoridad normativa. El modelo de las razones para la acción”, Doxa: Cuadernos de Filosofía del Derecho, núm. 10, 1991, pp. 67-90.

20 Véase Raz, Joseph, Between Authority and Interpretation..., cit. pp. 136 y 137; Raz, Joseph, The Morality of Freedom, Oxford, Clarendon Press, 1986, p. 71, y Raz, Joseph, Practical Reason and Norms, cit., pp. 193 y 194.

21 Raz, Joseph, Between Authority and Interpretation..., cit., p. 380.

22 Ibidem, pp. 136 y 137. 
exigen las razones en cada caso. Así, para que una autoridad sea legítima, se debe demostrar que un individuo cumple mejor las razones subyacentes al seguir sus directivas, que si hubiese ausencia absoluta de autoridad. Es decir, con la existencia de reglas emanadas de una autoridad, se logra que los agentes se conformen de manera más óptima con las razones subyacentes, que si ellos mismos determinaran lo que esas razones exigen y actuaran según el resultado de su deliberación. ${ }^{23}$

De acuerdo con la tesis de la autoridad legítima de Raz, la justificación de sus disposiciones depende de la mayor probabilidad de acierto de las autoridades al identificar las razones que, en todo caso, justifican la acción). ${ }^{24}$ Si se acepta esta tesis, entonces la jurisdicción de la autoridad legítima depende de que, en efecto, regule la clase de acciones y personas en las que se da dicho presupuesto. ${ }^{25}$ Esto quiere decir que aun cuando el derecho pretenda una jurisdicción ilimitada, y aun cuando las reglas secundarias no definan el límite de esa jurisdicción, las autoridades jurídicas sólo tienen jurisdicción respecto de aquellas razones y personas sobre las cuales tienen legitimidad moral para dirigir.

En suma, Raz está equivocado al pensar que una característica de la autoridad del derecho es su carácter comprehensivo. En efecto, si el AP de las reglas jurídicas depende de que existan los presupuestos de la legitimidad de la autoridad, entonces la autoridad sólo tiene la capacidad de excluir aquellas razones sobre las cuales existan las condiciones para el ejercicio legítimo de autoridad. Así las cosas, el AP de las reglas no depende solamente de las contingentes reglas secundarias de competencia, sino que depende fundamentalmente de que la persona o institución que ejerce el poder normativo de crear reglas jurídicas sea una autoridad legítima y que, por tanto, sea el caso que respecto de las acciones y personas que dirige se dan las condiciones de la autoridad como servicio. Además, esto implica que aun cuando se admita — como lo piensa Raz- que las reglas secundarias de competencia son de contenido contingente, no sig-

23 Raz, Joseph, The Morality of Freedom, cit., pp. 57-62.

24 Raz, Joseph, Between Authority and Interpretation..., cit., pp. 136 y 137.

25 Caracciolo, Ricardo, "El concepto de autoridad normativa...", cit., p. 73. 
nifica que estas reglas puedan tener cualquier contenido. Esto es así toda vez que las reglas secundarias que otorgan competencias a personas o instituciones respecto de las cuales no existen las condiciones que exige la autoridad como servicio, no tienen la capacidad de justificar la función excluyente de las reglas jurídicas que eventualmente profieran esas personas o instituciones. En una palabra, las reglas secundarias de competencia tienen una limitación necesaria: deben otorgar competencias a aquellas personas o instituciones que puedan ejercer autoridad legítima; y, no sobra advertirlo, esas condiciones no pueden ser creadas por esas mismas reglas secundarias de competencia.

Debe anotarse que tampoco tiene razón Raz cuando afirma la existencia de un AP de las reglas jurídicas por default. Según Raz, las reglas jurídicas - salvo aclaración en contrario- excluyen todas las razones objetivamente relevantes para la acción y, en particular, las razones que cuentan en contra de la acción exigida, las cuales, si prevalecen, llevarían a rechazar el requerimiento. ${ }^{26} \mathrm{Sin}$ embargo, y como se explicó en las anteriores líneas, si el AP de las reglas jurídicas depende de forma contingente de las reglas secundarias y del dominio práctico de la jurisdicción de la autoridad, no se encuentran razones para sostener una tesis del alcance por default.

Estas consideraciones son suficientes para mostrar que no es posible formular una tesis general acerca del AP. La jurisdicción de las autoridades depende tanto del contenido de las reglas secundarias (y razones auxiliares cuya finalidad consista, justamente, en afectar el ámbito de la exclusión) como del dominio legítimo de las autoridades. Esto quiere decir que el AP es una cuestión de grados de acuerdo con las reglas secundarias (de contenido contingente y variable), y de la jurisdicción legítima de las autoridades jurídicas. Por ello, es posible plantear la existencia de prácticas que pretenden una exclusión amplia, la cual reduce el número de razones no excluidas, y otras prácticas que pretenden una exclusión reducida, la cual amplía el conjunto de razones no excluidas.

26 Raz, Joseph, Between Authority and Interpretation..., cit., p. 392. 
En síntesis, las reglas son normativamente relevantes siempre que tengan la capacidad de excluir razones que son, a su vez, relevantes respecto de cómo se debe actuar o decidir. Sin embargo, las reglas tienen una función excluyente variable, y en ese sentido su AP (es decir el conjunto de razones excluidas y no excluidas) es distinto en cada ordenamiento jurídico (e incluso dentro de las diferentes prácticas que conforman esos ordenamientos). El AP de las reglas jurídicas es variable, y por tanto su definición contingente a cada ordenamiento o práctica jurídica, en tanto depende: 1) de la existencia y contenido de las reglas secundarias, y 2) de la tesis del dominio limitado de la autoridad. Toda vez que las reglas jurídicas tienen un AP variable y limitado (i. e. que no tienen la capacidad de excluir todas las razones objetivamente relevantes), habrá que preguntarse ahora cómo caracterizar la relación entre las reglas y el conjunto de razones no excluidas.

\section{RELACIONES CON LAS RAZONES NO EXCLUIDAS:} ANTINOMIAS Y EXCEPCIONES

En las consideraciones anteriores no se advirtió una ambigüedad en la explicación de la exclusión de las reglas jurídicas. El alcance de la exclusión puede referirse al alcance del ordenamiento jurídico concebido como un todo (el alcance del derecho), o al alcance de las reglas individualmente consideradas (el alcance de las reglas primarias). En realidad, el AP depende, en primera medida, del alcance de la exclusión del derecho (definido en sus reglas secundarias y según el dominio de la jurisdicción de sus autoridades), y en segunda medida, del alcance de las reglas primarias. Cada una de las reglas primarias, por tanto, tiene su propio alcance, de tal forma que esas reglas, individualmente consideradas, tienen la capacidad de excluir, por ejemplo, a otras reglas jurídicas. De acuerdo con estas precisiones, puede ocurrir que, en efecto, las reglas entren en conflicto con otras razones no excluidas (dentro de las cuales pueden aparecer, desde luego, otras reglas). El conjunto de razones no excluidas pueden ser normas pertenecientes al ordenamiento jurídico, o pertene- 
cer a otro ordenamiento o práctica, pero considerarse aplicables en virtud de las reglas secundarias. ${ }^{27}$

Las relaciones y conflictos entre las reglas y las normas no excluidas generan antinomias y excepciones. Una antinomia surge cuando para determinado caso (es decir, un tipo de acciones) existen consecuencias jurídicas incompatibles. ${ }^{28}$ Una antinomia puede ser: a) total, cuando las dos normas regulan las mismas propiedades, de forma que no hay posibilidad de que se aplique una de ellas sin entrar en conflicto con la otra; $b$ ) total-parcial, cuando el caso regulado por una de las normas es más restringido que el de la otra, y $c$ ) parcial-parcial, cuando las normas regulan propiedades que no resultan incompatibles. Lo importante es que en las dos últimas antinomias es posible aplicar las normas sin que éstas entren en conflicto. ${ }^{29}$

Los ordenamientos jurídicos suelen establecen reglas o condiciones de prevalencia para solucionar las contradicciones entre normas (por ejemplo, lex superior, lex posterior y lex specialis). Sin embargo, cuando existen dichas reglas o condiciones de prioridad, no existe un genuino conflicto normativo, que se resuelve una vez que se aplican las reglas y condiciones de prevalencia. Es decir, existe un conflicto normativo aparente cuando dos o más normas regulan un caso de forma incompatible pero el ordenamiento jurídico contempla una regla de prioridad que, debidamente aplicada, resuelve el conflicto. Existe un conflicto normativo genuino (una antinomia) cuando dos o más normas regulan un caso de forma incompatible y el ordenamiento jurídico no tiene previstas reglas o condiciones de prioridad para resolver el conflicto.

En los casos de las antinomias, el conflicto normativo debe resolverse de acuerdo con el balance del peso relativo de las razones en

27 Sobre el concepto de aplicabilidad, véase Navarro, Pablo y Rodríguez, Jorge, Deontic Logic and Legal Systems, Nueva York, Cambridge University Press, 2014, y Alchourrón, Carlos y Bulygin, Eugenio, Análisis lógico y derecho, Madrid, Centro de Estudios Constitucionales, 1991, pp. 195-198.

28 Guastini, Ricardo, Interpretar y argumentar, 2a. ed., trad. de S. Álvarez Medina, Madrid, Centro de Estudios Políticos y Constitucionales, pp. 117 y 118.

29 Ross, Alf, Sobre el derecho y la justicia, trad. de Genaro Carrió, Buenos Aires, Eudeba, 1963, pp. 164-168; Nino, Carlos S., Introducción al análisis del derecho, $2 \mathrm{a}$. ed., Buenos Aires, Astrea, 1984, pp. 274 y 275. 
conflicto. En efecto, cuando dos o más normas entran en conflicto (y, se reitera, no existen reglas o condiciones de prioridad), la determinación de cómo se debe actuar o decidir no depende de las reglas, sino del resultado de la evaluación de reglas en conflicto, lo cual, en definitiva, implica que se debe recurrir a un balance entre razones de primer orden. Siendo esto así, las reglas jurídicas (y el derecho) dejan de ser razones protegidas y de cumplir una función excluyente en el razonamiento práctico. Esto quiere decir que si se supone que una característica del funcionamiento normativo del derecho es su función excluyente en el razonamiento práctico (en el sentido que además de definir cómo actuar, excluye determinadas razones relevantes), cuando aparece una antinomia el asunto queda jurídicamente indeterminado, en tanto el derecho no define ni cómo se debe actuar ni qué razones son excluidas.

Podría objetarse que esta conclusión no es necesariamente cierta, pues, por ejemplo, si existe un conflicto entre dos reglas infraconstitucionales, el asunto no queda jurídicamente indeterminado, ya que el intérprete puede estar facultado para aplicar la regla que más se adecúe al contenido constitucional, o para aplicar directamente la Constitución. Sin embargo, resulta claro que en el primer caso lo que existe es una regla de prioridad, por lo cual el conflicto deviene en aparente, y en el segundo caso, no se plantea una regla de prioridad, sino un mecanismo distinto de solución de antinomias, consistente en aplicar una norma de mayor jerarquía. En este último caso, aunque exista un conflicto entre las normas infraconstitucionales, el asunto no queda jurídicamente indeterminado, pues justamente, para evitarlo, es posible aplicar la norma de mayor jerarquía. En cualquier caso, la hipótesis sobre aplicar directamente la Constitución en caso de conflicto es, sin duda, contingente, al depender de que ésta tenga en efecto una respuesta para el caso, y, como se verá enseguida, en las situaciones en las que la relación de dos normas contradictorias, donde, sin embargo, el derecho tiene definido un mecanismo para la resolución del conflicto, no surge una antinomia, sino una excepción.

Una regla, o razón en general, constituye una excepción para otra regla, siempre que existan normas con consecuencias jurídicas incompatibles, pero además - y a diferencia del caso de las antinomias - exista "una preferencia de la solución normativa de una de 
ellas sobre la otra". ${ }^{30}$ Para explica este tipo de relaciones normativas, resulta útil señalar tres formas en que pueden surgir las excepciones.

En primer lugar, las reglas secundarias pueden establecer excepciones genéricas en relación con todas las reglas primarias. Así, por ejemplo, es posible que la regla secundaria establezca que la autoridad $A$ tiene competencia para dictar las reglas $R$, y que los individuos deben seguirlas, salvo que aparezcan las circunstancias $q$ o $S$. Póngase por caso que $A$ dicta la regla $r$, la cual, por supuesto, hace parte del conjunto de reglas $R$, autorizadas por la regla de reconocimiento; así, un individuo debe seguir $r$, salvo que para el caso resulten aplicables $q$ o $s$.

En segundo lugar, cada una de las reglas $R$ puede contemplar excepciones específicas, y distintas a las provenientes de $q$ o $s$. En estos términos, por ejemplo, la regla $r 1$ establece que se debe hacer $\emptyset$, salvo que se acredite $m$. Un individuo, por tanto, debe hacer $\emptyset$, salvo que se acredite específicamente la excepción $m$, o de forma genérica, $q$ o $s$. Como se ve, una de las diferencias evidentes entre las excepciones genéricas y las específicas es que las primeras se refieren a todo el conjunto de $R$, mientras las segundas se circunscriben a las $r$ consideradas individualmente.

En tercer lugar, pueden surgir excepciones implícitas a consecuencia de la reconstrucción de las relaciones de las distintas reglas. Para explicar esto recuérdese la diferencia entre normas formuladas y normas derivadas. ${ }^{31}$ Las normas formuladas se refieren a cada una de las normas creadas por las autoridades jurídicas, y las derivadas corresponden a las consecuencias lógicas de cada una de las normas y de la reconstrucción de las relaciones con otras normas. $\mathrm{Si}$, como se ha dicho, en el ordenamiento jurídico existen reglas de prioridad, pueden aparecer normas derivadas cuando se reconstruyen adecuadamente las relaciones entre las normas en conflicto y las condiciones de prioridad. En consecuencia, la relación entre $r 1$ y $r 2$,

30 Navarro, Pablo y Rodríguez, Jorge, “Derrotabilidad y sistematización de normas”, Isonomía: Revista de Teoría y Filosofía del Derecho, núm. 13, 2000, pp. 61-85; Rodríguez, Jorge, "La derrotabilidad de las normas jurídicas", Isonomía: Revista de Teoría y Filosofía del Derecho, núm. 6, 1997, pp. 149-167, p. 159.

31 Alchourrón, Carlos y Bulygin, Eugenio, Normative Systems, Viena-Nueva York, Springer, 1971. 
por ejemplo, puede constituir una excepción siempre que: $a$ ) las soluciones normativas de ambas reglas resulten lógicamente incompatibles, y $b$ ) exista una preferencia de una sobre la otra. Si la regla de reconocimiento establece que las reglas con la propiedad $p$ prevalecen sobre las que no la tienen, y $r 1$ tiene la propiedad $p$, entonces $r 1$ se constituye en una excepción de $r 2$.

Se debe tener en cuenta que los conflictos entre reglas, en cuanto se puedan caracterizar como excepciones, no necesariamente generan una dificultad para la tesis de la función excluyente de las reglas. Aun cuando resulte común que las reglas individualmente consideradas estén expuestas a excepciones implícitas, es posible definir lo exigido por el derecho una vez que se reconstruyan las relaciones entre las normas en aplicación de las condiciones de prioridad. En realidad, la dificultad aparece cuando se afirma que una característica de las normas jurídicas es que sus excepciones no pueden ser reconstruidas de antemano, es decir, que son derrotables (DR). De acuerdo con la tesis de la derrotablidad, las normas jurídicas están abiertas a excepciones implícitas que no pueden ser enumeradas o reconstruidas ex-ante. Por lo tanto, que las reglas sean derrotables no es lo mismo que afirmar que tienen excepciones. Lo que está en juego en el análisis de la DR es la explicación de si es posible enumerar ex-ante todas las excepciones implícitas de las reglas. ${ }^{32}$ Las complejidades teóricas y prácticas que se generan con la DR son lo suficientemente complejas como para ser analizadas en este trabajo. Por ello, las siguientes líneas se limitan abordar la siguiente pregunta: ¿es una consecuencia necesaria de la relación entre las reglas y sus razones subyacentes que se generen excepciones implícitas que no pueden ser reconstruidas de antemano?

\section{LA DERROTABILIDAD DE LAS REGLAS}

Las reglas son el resultado de decisiones de las autoridades jurídicas que, luego de ponderar las diferentes razones de primer orden

32 Ferrer-Beltran, Jordi y Battista-Ratti, Giovanni, "Defeseability and legality: A Survey", en Ferrer Beltrán, J. y Battista Ratti, G. (eds.), The Logic of Legal Requirements: Essays on Defeasibility, Oxford, Oxford University Press, 2012, p. 11. 
(razones subyacentes), definen un conjunto de propiedades (el caso) al que otorgan determinada calificación jurídica. Para explicar la relación entre las reglas y sus razones subyacentes, Schauer parte de la distinción entre la formulación de las reglas (disposiciones jurídicas) y su justificación subyacente. Según él, en la disposición jurídica las autoridades formulan las propiedades que son consideradas relevantes respecto a la justificación de la regla. ${ }^{33}$ Sin embargo, para Schauer, la relación entre la regla y la justificación subyacente es de "causalidad probabilística"; es decir, que es "probable" que mediante la realización de la conducta definida en la regla se logre actuar de acuerdo con las razones subyacentes. ${ }^{34}$ Sin embargo, aun cuando el enunciado pueda ser verdadero para la mayoría de los casos, no es necesariamente verdadero para todos los casos. ${ }^{35}$

Existen casos en los que las disposiciones pueden ser sobreincluyentes o subincluyentes (experiencias recalcitrantes); ${ }^{36}$ son sobreincluyentes cuando regulan propiedades que no están en relación de causalidad probabilística con la justificación subyacente, y son subincluyentes cuando no contemplan propiedades que están en relación de causalidad probabilística con la justificación subyacente. Agrega Schauer que dependiendo de la respuesta a estas "experiencias recalcitrantes", se asume un modelo conversacional o un modelo atrincherado de toma de decisiones. ${ }^{37}$ En el primer modelo, las experiencias recalcitrantes se resuelven a favor de la justificación subyacente, y en el segundo modelo de toma de decisiones, se presume que el conflicto entre la regla y las razones subyacentes se resuelve a favor de la regla.$^{38}$ En los términos explicados antes, la diferencia fundamental entre estos modelos es que en el modelo conversacional las razones subyacentes no son en ningún caso excluidas.

33 Ibidem, pp. 17-31.

34 Ibidem, pp. 27-31.

35 Idem.

36 Schauer, Frederick, Thinking like a Lawyer: A new Introduction to Legal Reasoning, Cambridge, Harvard University Press, 2009, p. 27, y Schauer, Playing by the Rules, cit., pp. 31-34.

37 Ibidem, pp. 43-47.

38 Ibidem, pp. 47-53. 
Sin embargo, el atrincheramiento, y por tanto la exclusión de las razones subyacentes, no tiene por qué ser absoluto. Como se anotó en la primera parte de este trabajo, la exclusión de razones depende de dos variables: RS y DL. En ese sentido, la exclusión de las razones subyacentes (i. e. su atrincheramiento) depende igualmente de esas variables. Es decir, en tanto el AP de las reglas debe resolver también si las razones subyacentes de las reglas son o no excluidas (o, en términos de Schauer, si son o no atrincheradas), esto depende de las reglas secundarias de las prácticas jurídicas específicas y del dominio limitado de las autoridades jurídicas correspondientes.

Schauer, sin embargo, ha ido más lejos. Sostiene que la exclusión de las reglas puede ceder ante razones subyacentes (excluidas) particularmente exigentes. ${ }^{39}$ Tomar en consideración las razones subyacentes (excluidas) cuando resultan particularmente exigentes, implica que el individuo examine las razones de primer orden excluidas, para definir si una ocasión en particular forma parte de aquellas en que la regla puede ser desplazada. Sin embargo, podría cuestionarse si el hecho de admitir que los individuos puedan consultar las razones subyacentes no implica que la regla no excluya en absoluto. A esto, Schauer responde que las reglas permiten que los individuos examinen rápidamente las razones subyacentes para ver si es del caso que se descarte la exclusión. Con ello se asegura una diferencia en la toma de decisiones basada en reglas respecto de la toma de decisiones todas las cosas consideradas. ${ }^{40}$ La indagación exhaustiva de la corrección de esta tesis excede los límites y propósitos de este trabajo. En todo caso, debe tenerse en cuenta que, al admitir que las reglas pueden ser vencidas por sus razones subyacentes - como parece hacerlo Schauer-, se abre la discusión sobre la DR, y si es o no una propiedad necesaria de las reglas jurídicas. Afirmar que la fuerza de las reglas es presuntiva, podría ser otra forma de admitir la tesis de la necesaria DR, lo cual, por cierto, es rechazado por Schauer. ${ }^{41}$

39 Ibidem, pp. 196-206.

40 Ibidem, p. 91.

41 Schauer, Frederick, "Is defeasibility an essential property of law", en Ferrer Beltrán, J. y Battista Ratti, G. (eds.), The Logic of Legal Requirements: Essays on Defeasibility, Oxford, Oxford University Press, 2012, pp. 77-88. 
De cualquier forma, la cuestión es si de la relación entre las reglas y sus razones subyacentes surgen excepciones implícitas que no pueden ser identificadas de antemano, es decir, antes de aplicarlas a un caso concreto. En otras palabras, el problema consiste en definir si, como consecuencia de esa relación, las reglas son derrotables. Para efectuar este análisis es necesario previamente diferenciar la DR de la discusión acerca de si existe un deber moral de obedecer el derecho. ${ }^{42}$ Como lo resalta Bayón, la explicación de la derrotabilidad de las reglas no puede confundirse con la discusión acerca de si existe un deber moral de apartarse o seguirlas. De lo contrario, confundir la DR con el problema de la obediencia moral del derecho, se estaría liando de forma indebida la cuestión de si, en determinado caso, es moralmente adecuado seguir la norma jurídica, con la cuestión de qué se debe hacer en dicho caso de acuerdo con el derecho. ${ }^{43}$ En efecto, toda vez que resulta inteligible la existencia de una regla jurídica inderrotable, frente a la cual no exista el deber moral de obedecerla, o de una regla jurídica derrotable sobre la cual exista un deber moral de obedecerla, entonces es necesario explicar y diferenciar adecuadamente tales problemas.

Imaginemos una regla que exige vendar los ojos a los verdugos, con el fin de que no reconozcan al individuo sentenciado. Piénsese la hipótesis de un verdugo que pueda fallar por problemas de puntería, lo cual haría aconsejable retirar la venda de sus ojos. Supongamos que la práctica normativa del ejemplo prohíbe que, incluso en estos casos, se retire la venda a los verdugos. En esta situación habría, ceteris paribus, una regla inderrotable, sobre la cual (como sería presumible que se admita) no hay duda respecto a que no existe un deber moral de obedecerla. No se pretende con esta distinción resolver el complejo problema de si existe una separación conceptual entre los deberes jurídicos y los deberes morales. Se presupone simplemente que, aun cuando se admita la conexión entre los deberes jurí-

42 Para una revisión del problema del deber moral de obedecer el derecho, véase Edmundson, William, "Introduction", en Edmundson, William (ed.), The Duty to Obey the Law. Selected Philosophical Readings, Nueva York, Rowman \& Littlefield Publishers, 1999, pp. 1-17.

43 Bayón, Juan C., “¿Por qué es derrotable el razonamiento jurídico?”, Doxa: Cuadernos de Filosofía del Derecho, núm. 24, 2001, p. 51. 
dicos y los morales, existen diferencias conceptuales entre ellos, las cuales exigen herramientas explicativas diferentes.

Con base en las anteriores precisiones, la cuestión que la DR plantea - por lo menos para lo que se refiere al presente trabajo- es la adecuada caracterización de las consecuencias jurídicas generadas por la aparición de conflictos entre las reglas y sus razones subyacentes (experiencias recalcitrantes), y si una de las características de estas situaciones es la aparición de excepciones implícitas no identificables o reconstruibles de antemano. ${ }^{44} \mathrm{Al}$ respecto, es posible señalar la existencia de dos tesis.

De acuerdo con la primera, las reglas son derrotables como consecuencia del surgimiento de excepciones implícitas cuando, dentro de las razones subyacentes no excluidas, aparecen principios jurídicos (DR1). De acuerdo con la segunda, las reglas son derrotables como consecuencia de la facultad de incorporar nuevas excepciones (DR2). Según la tesis DR1, las experiencias recalcitrantes pueden generar que las reglas jurídicas estén sometidas “a excepciones implícitas que no pueden ser enumeradas exhaustivamente de antemano", de tal forma que "no sería posible precisar por anticipado, sino solo frente al caso individual, las circunstancias que operarían como genuinas condiciones suficientes para su aplicación" ${ }^{45}$ Y para

44 Desde luego, es posible definir la derrotabilidad en un sentido más amplio, de forma que incluya todos los casos en que una razón es superada por otra. De hecho, esa es la manera como, en algunos trabajos, Schauer ha concebido el concepto de derrotabilidad (véase "The limited domain of the law", Virginia Law Review, núm. 7, 2004, pp. 1909-1956). Sin embargo, considerando que son muy diversas las circunstancias en que una razón (incluidas las normas jurídicas) puede ser superada por otras razones, es necesario diferenciar con mayor precisión cada una de dichas circunstancias. Además de las limitaciones a la derrotabilidad que se analizan en este trabajo debe sumarse otra. El problema de la derrotabilidad que se plantea se dirige a establecer si las propiedades que no son explícitamente formuladas por las reglas jurídicas son o no relevantes al momento de definir si un caso determinado está jurídicamente regulado. Este asunto es distinto del problema de derrotabilidad en los términos que ha sido tratado por lo lógica deóntica contemporánea, en el marco de discusión de la existencia y adecuada explicación formal de los condicionales derrotables. Sobre esta delimitación, véase Zuleta, Hugo, Normas y justificación. Una investigación lógica, Madrid, Marcial Pons, 2008, pp. 131-138.

45 Sánchez Brígido, Rodrigo y Seleme, Hugo, "Derrotabilidad de normas jurí- 
la tesis DR2, como consecuencia de una experiencia recalcitrante, los ordenamientos jurídicos pueden reconocer la facultad, en particular a los jueces, de incorporar nuevas excepciones a las reglas. ${ }^{46}$

La tesis DR1 ha sido defendida por Bayón. Este autor sostiene que la DR es una consecuencia de la interacción entre principios y reglas. ${ }^{47}$ Los principios, según él, son razones de primer orden incorporadas por el derecho, que se constituyen en razones subyacentes de las reglas creadas por las autoridades jurídicas. En sus palabras, los Estados constitucionales hacen explícitas, en forma de principios, "sus condiciones sustanciales de justificación" ${ }^{48}$ La interacción entre reglas y principios lleva a que estos últimos generen excepciones a las reglas. Sin embargo, como no es posible, según Bayón, determinar de forma anticipada el "conjunto preciso de cada caso gobernado por un principio - porque éste puede concurrir en muchos de esos casos con otros principios, y no contamos con una jerarquización u ordenación estricta de los mismos-", tampoco es posible "determinar de antemano el conjunto preciso de excepciones". ${ }^{49}$ Como consecuencia de esta interacción, "cualquier regla está sujeta a excepciones implícitas por razones de principio". ${ }^{0}$ Bayón aclara que, en todo caso, la derrotabilidad es una propiedad contingente del derecho. Según él, la posibilidad de que convivan reglas y principios, y de que los operadores jurídicos puedan consultar los principios, depende de reglas secundarias contingentes.

No obstante, la explicación de Bayón, por una parte, es demasiado restrictiva, y, por otra —como lo explica J. Rodríguez-, no logra demostrar que necesariamente la interacción entre reglas y principios no pueda ser reconstruida y, por tanto, anticipada. En primer lugar, los problemas de las interacciones de las reglas con sus razones subyacentes no se pueden reducir a los Estados constitucio-

dicas", en Ortega, Santiago (ed.), Interpretación y razonamiento jurídico, Lima, Ara Editores, pp. 110-118.

46 Schauer, Frederick, "Is defeasibility an essential property of law", cit., pp. 77-88.

${ }^{47}$ Bayón, Juan C., “¿Por qué es derrotable el razonamiento jurídico?”, cit., p. 38.

48 Ibidem, p. 61.

49 Ibidem, p. 63.

50 Ibidem, pp. 53 y 54. 
nales contemporáneos (como parece asumirlo Bayón). En realidad, los ordenamientos jurídicos, a lo largo de la historia, han diseñado diferentes herramientas institucionales para tratar los problemas de las experiencias recalcitrantes, como por ejemplo, el argumento de la equidad o el poder de efectuar control constitucional concreto por vía de excepción. En segundo lugar, es un error sostener D1 con base en el argumento de la interacción entre reglas y principios. ${ }^{51}$ Como se explicó antes, la caracterización de la relación de las reglas con las razones no excluidas (así éstas sean sus razones subyacentes) se refiere o bien a una excepción, o bien a una antinomia. Así, cuando hay dos normas en conflicto (llámense principios o reglas), y no existen condiciones de prioridad, se está en presencia de una antinomia, de forma que el asunto queda indeterminado, pero no por la existencia de una norma derrotable (en el sentido de Bayón), sino por la existencia de soluciones lógicamente incompatibles. Por otra parte, cuando hay dos o más normas en conflicto, y existen condiciones de prioridad, se está en presencia de una excepción. ${ }^{52}$

Para Rodríguez, el derecho es el resultado de un conjunto finito de actos de creación normativa, de manera que el número de normas jurídicas es necesariamente limitado y susceptible de reconstrucción o identificación racional (otra cosa distinta es que en esa reconstrucción se defina que un asunto no está jurídicamente determinado). Además, los ordenamientos jurídicos están conformados por normas explícitas e implícitas. Si el conjunto de normas explícitas es finito, también lo es el conjunto de excepciones derivadas de las relaciones entre esas normas. Según esto, las normas derrotables no existen; lo que existen son excepciones implícitas a las normas. La existencia de principios no modifica esta conclusión. Si los principios están incorporados por el ordenamiento jurídico, entonces, como las reglas, se pueden reconstruir racionalmente..$^{53}$ En conse-

51 Rodríguez, Jorge, "La derrotabilidad de las normas jurídicas", cit., pp. 149167.

52 Una explicación similar puede verse en Rodríguez, Jorge y Sucar, Germán, "Las trampas de la derrotabilidad. Niveles de análisis de la indeterminación del derecho”, Doxa: Cuadernos de Filosofía del Derecho, núm. 21, 1998, pp. 371-402.

53 Rodríguez, Jorge, "La derrotabilidad de las normas jurídicas”, cit., p. 152. 
cuencia, es conceptualmente posible reconstruir el conjunto de soluciones normativas conformado por las normas implícitas y explícitas, y las excepciones implícitas que resulten de las relaciones entre normas (implícitas y explícitas) y las condiciones de prioridad; con esto se niega que la DR pueda ser explicada como la imposibilidad de prever excepciones. ${ }^{54}$

En términos simples, la crítica de Rodríguez a Bayón radica en que las excepciones implícitas apuntadas por éste son susceptibles de ser reconstruidas. Es decir, que en los ordenamientos jurídicos - como se vio en el apartado anterior - se presentan excepciones no incorporadas en las normas, que surgen de las relaciones sistemáticas con el resto de normas del ordenamiento jurídico, pero que, en todo caso, se pueden reconstruir. Es posible que Bayón esté confundiendo la eventual indeterminación lingüística en la formulación de principios con el problema de la derrotabilidad. Los principios, en general, son formulados mediante expresiones vagas, al menos en relación con la manera estándar en que se formulan las reglas; y si existe el deber de aplicar las mismas condiciones a las reglas y a los principios, entonces, pese a que las reglas sean semánticamente determinadas, la respuesta jurídica puede ser semánticamente indeterminada, a consecuencia de la vaguedad del principio.

De acuerdo con lo dicho hasta aquí, mediante las disposiciones jurídicas las autoridades (dentro de los límites lingüísticos) definen las propiedades relevantes que configuran los casos genéricos de las normas. En las situaciones en que aparecen experiencias recalcitrantes es necesario establecer si las razones subyacentes son o no relevantes al momento de establecer cómo el derecho califica normativamente el asunto. ${ }^{55}$ El problema, en palabras de Navarro y Rodríguez, se dirige a establecer el significado del enunciado "toda propiedad que no ha sido tomada como relevante es irrelevante". ${ }^{56}$

54 Navarro, Pablo y Rodríguez, Jorge, "Derrotabilidad y sistematización de normas”, Isonomía: Revista de Teoría y Filosofía del Derecho, núm. 13, 2000, pp. 61-85.

55 Alchourrón, Carlos, “On law and logic”, en Ferrer Beltrán, J. y Battista Ratti, G. (eds.), The Logic of Legal Requirements: Essays on Defeasibility, Oxford, Oxford University Press, 2012, pp. 39-52.

56 Navarro, Pablo y Rodríguez, Jorge, “Derrotabilidad y sistematización de normas", cit., 61-85. 
Según estos autores, dicho enunciado se puede entender en dos sentidos: uno prescriptivo y otro descriptivo.

De acuerdo con el sentido prescriptivo, dicha proposición significa que los ordenamientos jurídicos establecen que los operadores jurídicos "no deben introducir como relevantes otras propiedades que no sean aquellas que han sido expresamente tomadas como tales por el legislador ${ }^{\prime 2}{ }^{57}$ La existencia de esta regla depende contingentemente de las reglas secundarias existentes. Es decir, que es posible que las reglas secundarias excluyan aquellas consideraciones que no fueron explícitamente tomadas en cuenta por la autoridad que creó la regla. Pero es también posible que existan reglas secundarias que autoricen consultar a las razones subyacentes de las reglas y, en consecuencia, consideren relevantes propiedades que no han sido consideradas explícitamente como relevantes por parte de las autoridades en las disposiciones jurídicas. Así, el modelo atrincherado, entendido como aquel en el que los operadores jurídicos no deben introducir excepciones en aplicación de las razones subyacentes de las reglas, depende de la autorización de las reglas secundarias existentes en cada ordenamiento jurídico.

Por su parte, el sentido descriptivo de la proposición "toda propiedad que no ha sido tomada como relevante es irrelevante" puede ser negativo o positivo. El sentido negativo sostiene que si una propiedad no ha sido expresamente considerada como relevante, ella no ha sido considerada como irrelevante. Esta versión es cierta, pero trivial, y por tanto, no informativa. El sentido positivo (que considera la propiedad irrelevante si no ha sido expresamente considerada relevante) depende de la existencia de un principio de clausura, $i$. $e$. de una regla secundaría de existencia contingente..$^{58}$ En conclusión, tanto desde el punto de vista prescriptivo como del descriptivo la derrotabilidad de las reglas es contingente, pues depende, en definitiva, de las prácticas vigentes en las prácticas jurídicas, y de la existencia o el reconocimiento de reglas secundarias que definan un principio de clausura ( $v$. gr. el de que los operadores jurídicos no de-

58 Ibidem, p. 82. 
ben introducir como relevantes otras propiedades que no han sido expresamente tomadas como tales por el legislador).

Ahora bien, la tesis DR2, de la forma como es sostenida por Rodríguez y Navarro, implica que cuando aparecen experiencias recalcitrantes, es posible que el ordenamiento jurídico autorice a los operadores jurídicos para que incorporen nuevas excepciones en la regla con fundamento en las razones subyacentes. Tienen razón estos autores al sostener que la respuesta a esta cuestión, en cualquier caso, es contingente, pues depende de que las reglas secundarias de la práctica jurídica, en efecto, otorguen esta autorización. Sin embargo, si el derecho autoriza que los individuos consulten las razones subyacentes, no es claro cómo esto implica, de forma necesaria, que las excepciones a las normas sean nuevas. En efecto, las razones de primer orden - como se dijo antes- pueden ser normas incorporadas al ordenamiento jurídico o normas aplicables por autorización de las reglas secundarias del ordenamiento respectivo. Esas normas, en tanto son reconocidas por el derecho, pueden - como es reconocido por Rodríguez - ser reconstruidas racionalmente. Por lo tanto, la tesis DR2 no puede asumirse como una tesis general acerca de la caracterización de la DR. No es cierto que, necesariamente, la relación de las reglas con sus razones subyacentes implique la capacidad de incorporar nuevas excepciones, pues resulta conceptualmente posible reconstruirlas como excepciones implícitas.

Además, existe una diferencia entre la autorización de modificar las reglas como consecuencia de la experiencia recalcitrante y la posibilidad de tener en cuenta determinadas razones al momento de decidir si se sigue o no una regla. En este sentido, Schauer propone el siguiente ejemplo. Una regla exige a los conductores no sobrepasar los 80 kilómetros por hora. Existe además el principio de conservación y protección de la vida de las personas. Es posible que, en virtud de ese principio, se genere una excepción en aplicación de la regla, por ejemplo, cuando alguien los sobrepasa para llevar a tiempo a una persona herida al hospital. Sin embargo, en este caso, pese a que el principio se constituye en una excepción de la regla, no es posible concluir sin más que la regla haya sido modificada. Ello sólo ocurrirá en los casos en que el ordenamiento jurídico (sus reglas secundarias) autoricen a determinados operadores para mo- 
dificar el contenido de la reglas para ajustarlas a las experiencias recalcitrantes.

En suma, la DR no es una propiedad necesaria de las reglas. Su existencia depende de las reglas secundarias de las prácticas jurídicas en los casos en que consideren que las razones subyacentes resulten determinantes para establecer cómo se deben seguir las reglas. La DR, además, está en función de que esas razones subyacentes no sean identificables ex-ante. Con ello, la derrotabilidad del derecho quedaría reducida a los casos en que éste autoriza a los jueces a recurrir a razones subyacentes no jurídicas ( $v$. gr. algunas razones morales no incorporadas al derecho), las cuales no pueden ser identificadas previamente.

\section{CONCLUSIONES}

El AP de las reglas es una cuestión contingente que depende de dos variables: las reglas secundarias que determinan la competencia de las autoridades jurídicas, y el dominio limitado de la jurisdicción de la autoridad legítima. A partir de lo anterior se observó que la relación entre las reglas y las razones (o normas) no excluidas puede explicarse de forma adecuada a partir de las nociones de antinomia y excepción. A su vez, es posible diferenciar tres tipos de excepciones. Las excepciones genéricas (en las reglas secundarias), las excepciones específicas (establecidas en cada norma individualmente considerada) y las excepciones implícitas (que depende la relación con otras normas no excluidas y de las reglas de prioridad).

Por otra parte, se concluyó que - de conformidad con las reglas secundarias y dominio limitado de las autoridades jurídicas- es posible que las prácticas jurídicas incluyan o excluyan como consideraciones relevantes, al momento de definir lo que exigen sus reglas, a las razones subyacentes. En este contexto, la derrotabilidad es una propiedad contingente de las reglas que depende de la respuesta que den los ordenamientos jurídicos ante la eventual aparición de experiencias recalcitrantes.

En la caracterización de la derrotabilidad de las reglas se descartó la tesis DR1, en tanto que no logra demostrar que, necesariamente, 
la interacción entre reglas y principios no pueda ser reconstruida y, por tanto, anticipada. En relación con la tesis DR2, se concluyó que si las reglas secundarias autorizan consultar razones subyacentes, no significa que necesariamente se incorporen nuevas excepciones. Si las razones subyacentes son reconocidas por el derecho y, además, es posible reconstruirlas, entonces debe rechazarse que en tales casos el derecho faculte a incorporar nuevas excepciones.

Es posible concluir que la tesis DR1 resulta adecuada para los casos en que el derecho autorice recurrir a razones de primer orden que no pueden ser identificadas ex-ante (si esto es o no posible es una cuestión distinta y que no se pretende resolver en este trabajo). La tesis DR2 es adecuada sólo en el evento en que el derecho autorice a los individuos a aplicar normas o razones no contempladas por el ordenamiento jurídico respectivo. Pero lo cierto es que tanto DR1 como DR2 son tesis acerca de propiedades contingentes de las reglas jurídicas, de tal forma que ninguna puede asumirse como una proposición general acerca de la DR en el derecho.

Por último, de acuerdo con los argumentos expuestos, es posible finalizar este trabajo con dos conclusiones. Primera, siendo la derrotabilidad una propiedad contingente de las reglas jurídicas, no es posible elaborar una caracterización general acerca de cómo opera en cada una de las prácticas jurídicas. Segunda, mediante las disposiciones jurídicas, las autoridades se proponen crear reglas jurídicas. Por ello, suele afirmarse que las reglas jurídicas son el significado de las disposiciones jurídicas. En este orden de ideas, si dentro de los criterios significativos, según las reglas secundarias, aparece un conjunto específico de razones subyacentes, entonces no es posible afirmar, sin más, que los operadores modifiquen el derecho $(v$. gr. mediante la incorporación de nuevas excepciones).

\section{BIBLIOGRAFÍA}

Alchourrón, Carlos y Bulygin, Eugenio, Normative Systems, VienaNueva York, Springer, 1971.

Alchourrón, Carlos, Análisis lógico y derecho, Madrid, Centro de Estudios Constitucionales, 1991. 
Alchourrón, Carlos, "On law and logic”, en Ferrer Beltrán, J. y BAtTista RATTI, G. (eds.), The Logic of Legal Requirements: Essays on Defeasibility, Oxford, Oxford University Press, 2012.

BAYón, Juan C., “¿Por qué es derrotable el razonamiento jurídico?”, Doxa: Cuadernos de Filosofía del Derecho, núm. 24, 2001, en: http://www.cervantesvirtual.com/nd/ark:/59851/bmc8p6c0.

CARACCIOlo, Ricardo, "El concepto de autoridad normativa. El modelo de las razones para la acción”, Doxa: Cuadernos de Filosofía del Derecho, núm. 10, 1991, en: http://www.cervantes virtual.com/nd/ark:/59851/bmcm04g3.

EDMundson, William, "Introduction”, en Edmundson, William (ed.), The Duty to Obey the Law. Selected Philosophical Readings, Nueva York, Rowman \& Littlefield Publishers, 1999.

ENDICOTT, Timothy, "Interpretation, jurisdiction, and the authority of law", American Philosophical Association Newsletter on Law and Philosophy, núm. 2, 2007.

FERrer-Beltran, Jordi y Battista-RATti, Giovanni, "Defeseability and legality: A Survey", en FERrer Beltrán, J. y BATTISTA RATTI, G. (eds.), The Logic of Legal Requirements: Essays on Defeasibility, Oxford, Oxford University Press, 2012.

FinNis, Jhon, Natural law and natural rights, 2a. ed., Oxford, Oxford University Press, 2011.

GuASTINI, Ricardo, Interpretar y argumentar, 2a. ed., trad. de S. Álvarez Medina, Madrid, Centro de Estudios Políticos y Constitucionales.

HART, The concept of law, 2a. ed., P. Bulloch y J. Raz (eds.), Oxford, Clarendon Press, 1994.

Moore, Michael, "Authority, Law, and Razian Reasons", S. Cal. Law. Rev, núm. 3, 1989.

MARTIN, Margaret, Judging positivism, Oxford, Hart Publishing, 2014. Nino, Carlos S., Introducción al análisis del derecho, 2a. ed., Buenos Aires, Astrea, 1984. 
NAVArro, Pablo y Rodríguez, Jorge, "Derrotabilidad y sistematización de normas", Isonomía. Revista de Teoría y Filosofía del Derecho, núm. 13, 2000, en: http://www.cervantesvirtual. com/nd/ark:/59851/bmc891j3.

Navarro, Pablo y Rodríguez, Jorge, Deontic Logic and Legal Systems, Nueva York, Cambridge University Press, 2014.

Perry, Stephen R., "Judicial Obligation, Precedent and the Common Law", Oxford Journal of Legal Studies, núm. 2, 1987, en: https://doi.org/10.1093/ojls/7.2.215.

Postema, Gerald, "Law's autonomy and public practical reason", en GEORGE, Robert P., The Autonomy of law. Essays on legal positivism, Oxford, Oxford University Press, 1996.

RAZ, Joseph, The Authority of Law. Essays on Law and Morality, Oxford, Clarendon Press, 1979.

RAZ, Joseph, The Morality of Freedom, Oxford, Clarendon Press, 1986.

RAZ, Joseph, Practical Reason and Norms, 2a. ed., Oxford, Oxford University Press, 1990.

RAz, Joseph, Between Authority and Interpretation: on the Theory of Law and Practical Reason, Oxford, Oxford University Press, 2009.

RodEnAS, Ángeles, Los intersticios del derecho. Indeterminación, validez y positivismo jurídico, Madrid, Marcial Pons, 2012.

RoDRíGuEz, Jorge, "La derrotabilidad de las normas jurídicas”, Isonomía: Revista de Teoría y Filosofía del Derecho, núm. 6, 1997, en: http://www.cervantesvirtual.com/nd/ark:/59851/ bmc0p1c3.

RoDRÍGUEZ, Jorge y SuCAR, Germán, "Las trampas de la derrotabilidad. Niveles de análisis de la indeterminación del derecho", Doxa: Cuadernos de Filosofía del Derecho, núm. 21, 1998, pp. 371402, en: http://www.cervantesvirtual.com/nd/ark:/59851/ bmc $3 t 9 w 2$.

Ross, Alf, Sobre el derecho y la justicia, trad. de Genaro Carrió, Buenos Aires, Eudeba, 1963. 
SÁnchez BRígido, Rodrigo y SEleme, Hugo, "Derrotabilidad de normas jurídicas", en ORTEGA, Santiago (ed.), Interpretación y razonamiento jurídico, Lima, Ara Editores.

Schauer, Fredrick, Playing by the Rules. A philosophical Examination of Rule-Based Decision-Making in Law and in Life, Oxford, Oxford University Press, 1991.

SCHAUER, Fredrick, "The limited domain of the law", Virginia Law Review, núm. 7, 2004.

SchAuER, Fredrick, "A Critical Guide to Vehicles in the Park", N. Y. U. L. Rev, núm. 83, 2008, en: http://www.nyulawreview.org/issues/ volume-83-number-4/critical-guide-vehicles-park.

ScHAUER, Fredrick, Thinking like a lawyer: A new introduction to legal Reasoning, Cambridge, Harvard University Press, 2009.

SCHAUER, Fredrick, "Is defeasibility an essential property of law", en FERrer Beltrán, J. y BAtTista RATTI, G. (eds.), The Logic of Legal Requirements: Essays on Defeasibility, Oxford, Oxford University Press, 2012.

Schauer, Fredrick, "On the Open Texture of Law", Grazer Philosophische Studien, núm. 87, 2013.

Wallace, R. Jay, "Practical Reason", en E. Zalta (ed.), The Stanford Encyclopedia of Philosophy, consultado el 16 de marzo de 2016 en: https://plato.stanford.edu/archives/sum2014/en tries/practical-reason/.

Zuleta, Hugo, Normas y justificación. Una investigación lógica, Madrid, Marcial Pons, 2008. 